Article

\title{
Assessment of Metabolic Interaction between Repaglinide and Quercetin via Mixed Inhibition in the Liver: In Vitro and In Vivo
}

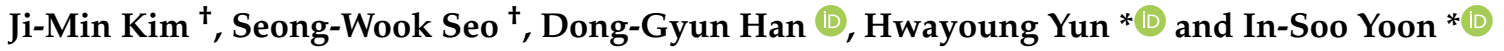 \\ Department of Manufacturing Pharmacy, College of Pharmacy, Pusan National University, Busan 46241, Korea; \\ jiminkim@pusan.ac.kr (J.-M.K.); sswook@pusan.ac.kr (S.-W.S.); hann9607@pusan.ac.kr (D.-G.H.) \\ * Correspondence: hyun@pusan.ac.kr (H.Y.); insoo.yoon@pusan.ac.kr (I.-S.Y.); Tel.: +82-51-510-2810 (H.Y.); \\ +82-51-510-2806 (I.-S.Y.) \\ + These authors contributed equally to this work.
}

Citation: Kim, J.-M.; Seo, S.-W.; Han, D.-G.; Yun, H.; Yoon, I.-S.

Assessment of Metabolic Interaction between Repaglinide and Quercetin via Mixed Inhibition in the Liver: In Vitro and In Vivo. Pharmaceutics 2021, 13, 782. https://doi.org/10.3390/ pharmaceutics 13060782

Academic Editor: Im-Sook Song

Received: 17 March 2021

Accepted: 20 May 2021

Published: 23 May 2021

Publisher's Note: MDPI stays neutral with regard to jurisdictional claims in published maps and institutional affiliations.

Copyright: (c) 2021 by the authors. Licensee MDPI, Basel, Switzerland. This article is an open access article distributed under the terms and conditions of the Creative Commons Attribution (CC BY) license (https:// creativecommons.org/licenses/by/ $4.0 /)$.

\begin{abstract}
Repaglinide (RPG), a rapid-acting meglitinide analog, is an oral hypoglycemic agent for patients with type 2 diabetes mellitus. Quercetin (QCT) is a well-known antioxidant and antidiabetic flavonoid that has been used as an important ingredient in many functional foods and complementary medicines. This study aimed to comprehensively investigate the effects of QCT on the metabolism of RPG and its underlying mechanisms. The mean (range) $\mathrm{IC}_{50}$ of QCT on the microsomal metabolism of RPG was estimated to be $16.7(13.0-18.6) \mu \mathrm{M}$ in the rat liver microsome (RLM) and $3.0(1.53-5.44) \mu \mathrm{M}$ in the human liver microsome (HLM). The type of inhibition exhibited by QCT on RPG metabolism was determined to be a mixed inhibition with a $\mathrm{K}_{\mathrm{i}}$ of $72.0 \mu \mathrm{M}$ in RLM and $24.2 \mu \mathrm{M}$ in HLM as obtained through relevant graphical and enzyme inhibition model-based analyses. Furthermore, the area under the plasma concentration versus time curve (AUC) and peak plasma concentration $\left(\mathrm{C}_{\max }\right)$ of RPG administered intravenously and orally in rats were significantly increased by $1.83-$ and 1.88-fold, respectively, after concurrent administration with QCT. As the protein binding and blood distribution of RPG were observed to be unaltered by QCT, it is plausible that the hepatic first-pass and systemic metabolism of RPG could have been inhibited by QCT, resulting in the increased systemic exposure (AUC and $\mathrm{C}_{\max }$ ) of RPG. These results suggest that there is a possibility that clinically significant pharmacokinetic interactions between QCT and RPG could occur, depending on the extent and duration of QCT intake from foods and dietary supplements.
\end{abstract}

Keywords: drug-phytochemical interaction; hepatic metabolism; mixed inhibition; quercetin; repaglinide

\section{Introduction}

Repaglinide (RPG; Figure 1), a rapid-acting meglitinide analogue, is an oral hypoglycemic agent for patients with type 2 diabetes mellitus [1]. It lowers postprandial blood glucose levels by promoting insulin secretion from pancreatic $\beta$-cells [2]. RPG reduces the risk of hypoglycemia by stimulating insulin secretion only when blood glucose levels are higher than normal, whereas sulfonylureas induce insulin secretion even at low blood glucose levels [3,4]. Additionally, treatment with RPG has been shown to improve oxidative stress indices in type 2 diabetic patients, potentially reducing the risk of diabetes-associated vascular disease [5]. The oral absorption of RPG is rapid and complete but its bioavailability is low because of considerable first-pass metabolism [6]. RPG is primarily eliminated via cytochrome P450 (CYP)-mediated oxidative metabolism in the liver; in particular, both CYP2C8 and CYP3A4 are the principal CYP isoforms responsible for the biotransformation of RPG [7,8].

Over the past decades, bioactive flavonoids from various medicinal herbs and dietary supplements have gained increasing interest because of their important roles in complementary and alternative medicines $[9,10]$. A previous literature review of 18 studies over 
9 countries indicated that the prevalence of complementary and alternative medicine use among people with diabetes ranges from $17 \%$ to $72.8 \%$ [11]. Quercetin (QCT; Figure 1), one of the most extensively explored flavonoids, is commonly found in many fruits, vegetables, and grains $[12,13]$. QCT is a widely recognized nutraceutical commercially available in capsule and tablet forms, consumed at a daily dose of $1 \mathrm{~g}$ or more [14]. It is a potent antioxidant and anti-inflammatory phytochemical that exerts a wide range of protective and therapeutic activities against arthritis, cancer, cardiovascular disease, diabetes, neurodegenerative disease, and obesity [15]. In particular, the mechanisms of the antidiabetic action of QCT include the inhibition of intestinal glucose absorption, stimulation of insulin secretion, and enhancement of peripheral glucose utilization, which contribute to improving whole-body glucose homeostasis [16]. Thus, there is a possibility that QCT can be used as a complementary medicine concurrently with RPG for the prevention and treatment of type 2 diabetes.<smiles>CCOc1cc(CC(=O)N[C@H](CC(C)C)c2ccccc2N2CCCCC2)ccc1C(=O)O</smiles>

Repaglinide<smiles>O=c1c(O)c(-c2ccc(O)c(O)c2)oc2cc(O)cc(O)c12</smiles>

Quercetin

Figure 1. Chemical structures of repaglinide and quercetin.

QCT is eliminated mainly through phase II metabolism, such as glucuronidation, sulfation, and methylation in the liver [17]. QCT has been used as a selective CYP2C8 inhibitor in CYP phenotyping studies [18-20]; however, some reports have shown the inhibitory effects of QCT on other CYP isozymes [21,22]. In particular, a previous study revealed that QCT profoundly inhibited the activity of several CYPs including CYP2C8 and CYP3A4 [23], while another more recent study reported that QCT significantly inhibited CYP3A4 activity with a $\mathrm{K}_{\mathrm{i}}$ of $15.4 \mu \mathrm{M}$ [24]. Furthermore, it is important to note that several studies have reported significant drug interactions of RPG with CYP2C8 and CYP3A4 inhibitors. Systemic exposure to orally administered RPG was significantly increased by CYP2C8 inhibitors such as trimethoprim (1.6-2-fold) and clopidogrel (3.1-5.1-fold) $[25,26]$ and by CYP3A4 inhibitors such as telithromycin (1.8-fold) and itraconazole (1.4-fold) [27,28]. Indeed, a previous study reported that QCT $(25 \mu \mathrm{M})$ inhibited the in vitro metabolism of RPG $(0.2 \mu \mathrm{M})$ by $58 \%$ in human liver microsome (HLM) [8], and another study reported the $\mathrm{K}_{\mathrm{i}}$ of $0.61 \mu \mathrm{M}$ for the inhibitory effect of QCT on in vitro metabolism of RPG in HLM [29]. Thus, there is a possibility of in vivo herb-drug interactions between QCT and RPG, but relevant information is currently lacking. This strongly suggests an immediate need for further investigation on this issue to avoid adverse reactions and optimize drug therapy.

Therefore, the present study aimed to comprehensively investigate the effects of QCT on the metabolism and pharmacokinetics of RPG. The inhibitory effect of QCT on the metabolism of RPG and its mechanisms were studied in HLM and rat liver microsomes (RLM). Next, the in vivo pharmacokinetic interactions between QCT and RPG were evaluated in a rat model. The protein binding and blood distribution of RPG were also examined.

\section{Materials and Methods}

\subsection{Materials}

RPG (purity $>98 \%$ ), QCT (purity $\geq 95 \%$ ), and ketoconazole (used as an internal standard; purity $\geq 98 \%$ ) were purchased from Tokyo Chemical Industry Co. (Tokyo, Japan) Ethanol, dimethyl sulfoxide, polyethylene glycol 400 (PEG 400), carboxymethyl cellulose 
(CMC), potassium phosphate monobasic/dibasic, $\beta$-Nicotinamide adenine dinucleotide phosphate (NADPH), and phosphate-buffered saline (PBS) were purchased from SigmaAldrich (St. Louis, MO, USA). Pooled male Sprague-Dawley rat plasma and pooled male human plasma were purchased from Innovative Research, Inc. (Novi, MI, USA) Pooled HLM and RLM were purchased from BD-Genetech (Woburn, MA, USA).

\subsection{Protein Binding and Blood Distribution Studies}

The unbound fractions of RPG and QCT in plasma $\left(f_{u P}\right)$ and hepatic microsomes $\left(f_{\mathrm{uMIC}}\right)$ were measured through an equilibrium dialysis method using a rapid equilibrium dialysis (RED) device (Thermo Fisher Scientific, Inc., Waltham, MA, USA) as described previously [30-33]. The microsomes and 20-fold diluted plasma were spiked with either RPG alone or in combination with QCT yielding final concentrations of $5 \mu \mathrm{M}$ for both compounds. A $200 \mu \mathrm{L}$ spiked samples and $400 \mu \mathrm{L}$ PBS were placed into the "sample" and "buffer" chambers of the RED device, respectively. After 4-h incubation to equilibrate between the buffer and plasma compartments, the RED plate was sampled from both compartments. The samples were matrix-matched for analysis by addition of either diluted plasma or buffer; (a) blank diluted plasma added to the buffer samples and (b) blank buffer added to the diluted plasma sample, at a ratio of 50:50 $\mathrm{v} / \mathrm{v}$. The unbound fractions in microsomes and diluted plasma were determined by dividing the analyte/IS peak area ratios of the (a) sample by those of the (b) sample. The unbound fraction in diluted plasma $\left(f_{u, d}\right)$ was converted to the unbound fraction in undiluted plasma $\left(f_{u}\right)$ using a Kalvass equation as below (DF: dilution factor) [33].

$$
\mathrm{f}_{\mathrm{u}}=\frac{1 / \mathrm{DF}}{\left[\left(1 / \mathrm{f}_{\mathrm{u}, \mathrm{d}}\right)-1\right]+1 / \mathrm{DF}}
$$

The blood-to-plasma concentration ratio $\left(\mathrm{R}_{\mathrm{B}}\right)$ of $\mathrm{RPG}$ was determined as described previously [34]. Briefly, $1 \mathrm{~mL}$ of fresh blood was spiked with either RPG alone or in combination with QCT, yielding a final concentration of $5 \mu \mathrm{M}$ for both compounds, and then incubated at $37^{\circ} \mathrm{C}$ for $60 \mathrm{~min}$. A plasma sample was obtained by centrifugation of the blood sample at $2000 \times g$ for $5 \mathrm{~min}$. The concentrations of RPG in $50 \mu \mathrm{L}$ of the plasma samples were determined using a validated high-performance liquid chromatography (HPLC) method.

\subsection{In Vitro Microsomal Metabolism Study}

The concentration-dependent disappearance of RPG in the RLM and HLM was evaluated to investigate the kinetics of the hepatic CYP-mediated metabolism of RPG. A microsomal reaction mixture consisting of microsomes $(0.3 \mathrm{mg} / \mathrm{mL}), 1 \mathrm{mM}$ NADPH, $50 \mathrm{mM}$ phosphate buffer, and 1-500 $\mu \mathrm{M}$ RPG in distilled water (DW) was prepared, at a total volume of $200 \mu \mathrm{L}$. At 0,30 , and $60 \mathrm{~min}$ after starting the metabolic reaction, a $50 \mu \mathrm{L}$ aliquot of the incubation mixture was sampled and transferred to a clean 1.5-mL microcentrifuge tube containing $150 \mu \mathrm{L}$ of ice-cold acetonitrile to terminate the metabolic reaction. Following centrifugation at $15,000 \times g$ for $10 \mathrm{~min}, 150 \mu \mathrm{L}$ of the resultant supernatant was obtained and the concentration of RPG in the sample was determined using the HPLC method.

\subsection{In Vitro Metabolic Inhibition Study}

To construct dose-response curves to determine the inhibitory effect of QCT on the hepatic metabolism of RPG, a microsomal incubation mixture consisting of RLM or HLM (0.5 mg/mL microsomal protein), $1 \mathrm{mM} \mathrm{NADPH,} 50 \mathrm{mM}$ potassium phosphate buffer, $3 \mu \mathrm{M}$ RPG, and nine different concentrations of QCT $(0,0.1,0.5,1,5,10,50,100$, and $200 \mu \mathrm{M})$ were prepared, at a total volume of $200 \mu \mathrm{L}$. To construct Dixon plots for the inhibitory effects of QCT on the hepatic metabolism of RPG, five different concentrations of RPG $(1,3,10,30$, and $100 \mu \mathrm{M})$, and five different concentrations of QCT $(0,1,30,100$, and $200 \mu \mathrm{M}$ ) were used. Microsomal incubation and sample preparation were performed as described in the Section 2.3. 


\subsection{Animals}

Sprague-Dawley rats (approximately $250 \mathrm{~g}$ ) were purchased from Samtako Bio Korea Co. (Gyeonggi-do, South Korea) Rats were housed in ventilated rat cages (Tecniplast USA, West Chester, PA, USA) with access to standard rat chow (Agribrands Purina Canada Inc., Levis, Canada) and water ad libitum, and were allowed to acclimatize for one week prior to the experiments. Protocols for the animal studies were reviewed and approved in accordance with the guidelines of the Institutional Animal Care and Use Committee of Pusan National University (Busan, South Korea; date of approval: 4 May 2020; approval number: PNU-2020-2602).

\subsection{In Vivo Pharmacokinetic Study in Rats}

Rats were anesthetized via intramuscular injection of $10 \mathrm{mg} / \mathrm{kg}$ zoletil [35]. The femoral vein and artery of the rats were cannulated using a polyethylene tube (BD Medical, Franklin Lakes, NJ, USA). After recovery from anesthesia, a single intravenous or oral dose $(0.4 \mathrm{mg} / \mathrm{kg})$ of RPG with or without a single simultaneous intravenous dose $(25 \mathrm{mg} / \mathrm{kg})$ or oral dose $(100 \mathrm{mg} / \mathrm{kg})$ of QCT was administered to the rats. The vehicle solutions for the intravenous and oral doses were composed of PEG 400 and aqueous $0.3 \%$ CMC solution $(50: 50 v / v)$. Approximately $300 \mu \mathrm{L}$ of blood was collected via the femoral artery at $0,1,5$, $15,30,60,90,120,180$, and $240 \mathrm{~min}$ after intravenous injection and at 10, 20, 30, 45, 60, 90, 120,180 , and $240 \mathrm{~min}$ after oral administration. After centrifugation of the blood sample at $2000 \times g$ at $4{ }^{\circ} \mathrm{C}$ for $5 \mathrm{~min}, 120 \mu \mathrm{L}$ of the resulting supernatant (plasma) was obtained and the concentration of RPG in the sample was determined using the HPLC method.

\subsection{HPLC Analysis}

The concentrations of RPG and QCT in the buffer, microsomes, and (diluted) plasma samples were determined as reported previously [36,37], with slight modifications. For RPG, $50 \mu \mathrm{L}$ of the sample (or $120 \mu \mathrm{L}$ of the plasma sample obtained from the in vivo pharmacokinetic study) was deproteinized with $300 \mu \mathrm{L}$ of acetonitrile that contain ketoconazole (internal standard; $100 \mathrm{ng} / \mathrm{mL}$ ). For QCT, $200 \mu \mathrm{L}$ of the microsome sample or diluted plasma was deproteinized with $400 \mu \mathrm{L}$ of acetonitrile that contained lapatinib (internal standard; $2000 \mathrm{ng} / \mathrm{mL}$ ). After vortex mixing and centrifugation at $15,000 \times g$ for $10 \mathrm{~min}$, the resulting supernatant was transferred to a clean $1.5-\mathrm{mL}$ microcentrifuge tube and dried under nitrogen gas at room temperature. The residue was reconstituted with $50 \mu \mathrm{L}$ of a mobile phase. After vortex mixing and centrifugation at $15,000 \times g$ for $10 \mathrm{~min}, 40 \mu \mathrm{L}$ of the resulting supernatant was injected into the HPLC column (length $250 \mathrm{~mm}$, inner diameter $4.6 \mathrm{~mm}$, particle size $5 \mu \mathrm{m}$, pore size $100 \AA$ A; Phenomenex, Torrance, CA, USA). For RPG, isocratic elution of a mobile phase consisting of $10 \mathrm{mM}$ phosphate buffer ( $\mathrm{pH}$ 6.0) and acetonitrile $(46.4: 53.6, v / v)$ was performed at a flow rate of $1 \mathrm{~mL} / \mathrm{min}$; the column effluent was monitored by a fluorescence detector (RF-20A; Shimadzu Co., Kyoto, Japan) at $240 \mathrm{~nm}$ $\left(\lambda_{\mathrm{ex}}\right) / 380 \mathrm{~nm}\left(\lambda_{\mathrm{em}}\right)$ at room temperature. For QCT, gradient elution of a mobile phase consisting of $0.1 \%$ TFA in water (solvent $\mathrm{A}$ ) and acetonitrile (solvent $\mathrm{B}$ ) was performed at a flow rate of $1 \mathrm{~mL} / \mathrm{min}$, and the procedure was as follows (solvent $A$ : solvent $B, v / v$ ): started at 75:25 at $0 \mathrm{~min}$, ramped from 75:25 to 60:40 for $13 \mathrm{~min}$, back to 75:25 for $0.1 \mathrm{~min}$, and maintained for $6.9 \mathrm{~min}$ (total run time: $20 \mathrm{~min}$ ); the column effluent was monitored by an ultraviolet detector (SPD-20A; Shimadzu Co., Kyoto, Japan) at $254 \mathrm{~nm}$ at $40{ }^{\circ} \mathrm{C}$. The lower limit of quantitation limit (LLOQ) of the HPLC methods were $10 \mathrm{ng} / \mathrm{mL}$ (buffer and plasma samples) and $50 \mathrm{ng} / \mathrm{mL}$ (microsome samples) for RPG and $100 \mathrm{ng} / \mathrm{mL}$ for QCT. The validation parameters for the HPLC methods were listed in Tables S1 and S2. 


\subsection{Data Analysis}

A single-site Michaelis-Menten Equation was simultaneously fitted to the substrate (RPG) concentration $([\mathrm{S}] ; \mu \mathrm{M})$ as follows versus initial metabolic rate $(\mathrm{V} ; \mathrm{pmol} / \mathrm{min} / \mathrm{mg}$ protein):

$$
\mathrm{V}=\frac{\mathrm{V}_{\max } \times[\mathrm{S}]}{\mathrm{K}_{\mathrm{m}}+[\mathrm{S}]}
$$

where $V_{\max }$ and $\mathrm{K}_{\mathrm{m}}$ are the maximal metabolic rate and Michaelis-Menten constant, respectively. The intrinsic metabolic clearance $\left(\mathrm{CL}_{\text {int }}\right)$ was calculated as $\mathrm{V}_{\max } / \mathrm{K}_{\mathrm{m}}$. The half maximal inhibitory concentration $\left(\mathrm{IC}_{50}\right)$ of QCT for the hepatic metabolism of RPG was determined via nonlinear regression using GraphPad Prism software (version 5.01; GraphPad Software, San Diego, CA, USA) according to the four-parameter logistic equation:

$$
Y=\operatorname{Min}+\frac{\operatorname{Max}-\operatorname{Min}}{1+\left(\frac{X}{C_{50}}\right)^{-P}}
$$

where $\mathrm{X}$ and $\mathrm{Y}$ are the inhibitor concentrations and response, respectively. Max and Min are the initial and final $Y$ values, respectively, and the power $P$ represents the Hill coefficient. The type of inhibition of QCT on the hepatic metabolism of RPG was determined graphically using a Dixon plot. The inhibition constant $\mathrm{K}_{\mathrm{i}}$ of $\mathrm{QCT}$ on the hepatic metabolism of RPG was determined via nonlinear regression using a GraphPad Prism, according to the mixed-model enzyme inhibition equation:

$$
\mathrm{Y}=\frac{\mathrm{V}_{\max } \times \mathrm{X}}{\mathrm{K}_{\mathrm{m}} \times\left(1+\frac{\mathrm{I}}{\mathrm{K}_{\mathrm{i}}}\right)+\mathrm{X} \times\left(1+\frac{\mathrm{I}}{\alpha \times \mathrm{K}_{\mathrm{i}}}\right)}
$$

where $\mathrm{X}, \mathrm{Y}$, and I are the substrate concentration, enzyme activity, and inhibitor concentration, respectively. $V_{\max }$ and $\mathrm{K}_{\mathrm{m}}$ are the same as those defined in Equation (2). The parameter $\alpha$ is indicative of the inhibition type. The mixed model is a general equation that includes competitive, uncompetitive, and noncompetitive inhibition as special cases. When $\alpha=1$, the mixed model is identical to a noncompetitive inhibition. When $\alpha$ is very large $(\alpha \rightarrow \infty)$ or very small $(\alpha \rightarrow 0)$, the mixed model becomes identical to competitive inhibition or uncompetitive inhibition, respectively. In the other cases $(\alpha \neq 1)$, the mixed model describes mixed inhibition.

Non-compartmental analysis (WinNonlin, version 3.1, NCA200 and 201; Certara, Inc., Princeton, NJ, USA) was conducted to estimate the following pharmacokinetic parameters: total area under the plasma concentration-time curve from time zero to time infinity (AUC); total body clearance (CL, calculated as dose/AUC); terminal half-life $\left(\mathrm{t}_{1 / 2}\right)$; and apparent volume of distribution at steady state $\left(\mathrm{V}_{\mathrm{ss}}\right)$. For comparison, the extent of absolute oral bioavailability (F; expressed as percent of dose administered) was calculated by dividing the dose-normalized AUC after oral administration by the dose-normalized AUC after intravenous injection. The peak plasma concentration $\left(\mathrm{C}_{\max }\right)$ and time to reach $\mathrm{C}_{\max }\left(\mathrm{T}_{\max }\right)$ were obtained directly from the measured experimental data.

\subsection{Statistical Analysis}

$p$-values $<0.05$ were considered statistically significant. They were calculated using the unpaired $t$-test for comparison between two means or one-way analysis of variance (ANOVA) with post-hoc Tukey's honestly significant difference test for comparison among three means. Unless indicated otherwise, all data are expressed as the mean \pm standard deviation, except for $\mathrm{T}_{\max }$, which is expressed as median (range), rounded to three significant figures.

\section{Results}

\subsection{Effects of QCT on the Protein Binding and Blood Distribution of RPG}

The $f_{u P}, f_{u M I C}$, and $R_{B}$ of RPG in the absence and presence of QCT are shown in Figure 2. The $f_{u P}$ of RPG was $0.0533 \pm 0.0060$ and $0.0761 \pm 0.0094$ in human and rat 
plasma, respectively, indicating extensive plasma protein binding. The $\mathrm{f}_{\mathrm{uMIC}}$ of RPG was $0.620 \pm 0.152$ and $0.671 \pm 0.009$ in HLM and RLM, respectively, indicating low to moderate microsomal protein binding. The $\mathrm{f}_{\mathrm{uP}}$ and $\mathrm{f}_{\mathrm{uMIC}}$ of RPG were not significantly altered by the presence of QCT $(p \geq 0.0609)$. The rat and human $R_{B}$ of RPG observed in the present study were $0.869 \pm 0.043$ and $0.847 \pm 0.021$, respectively, and they were not significantly altered by the presence of QCT ( $p \geq 0.054)$. These results indicated minimal effects of QCT on the protein binding and blood distribution of RPG.

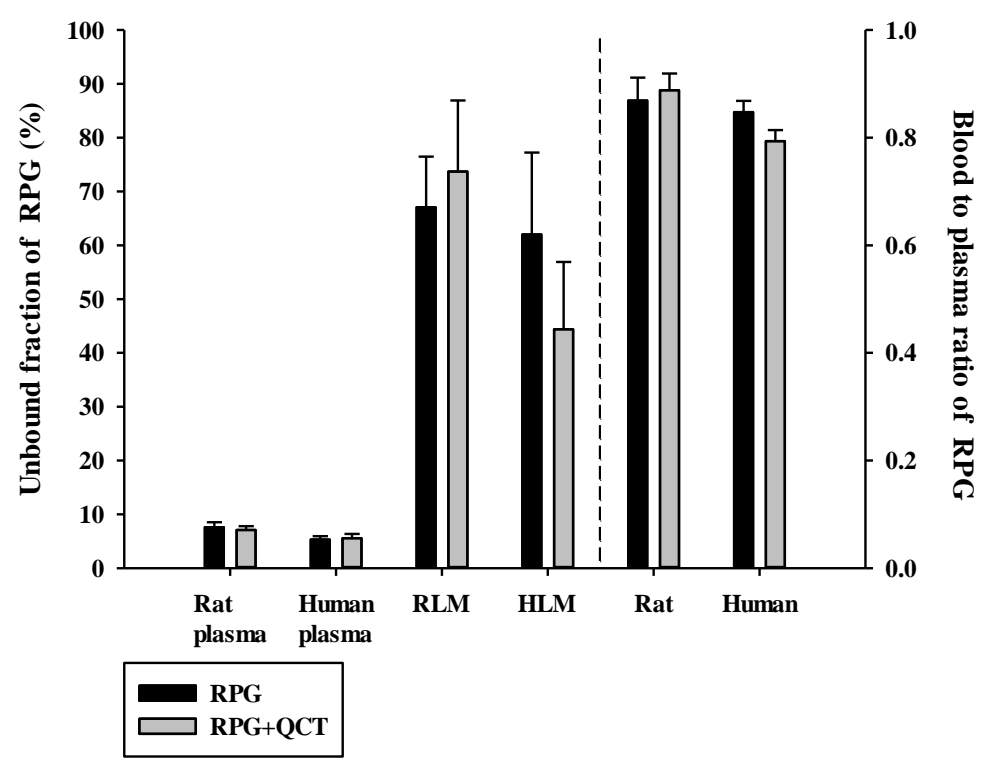

Figure 2. Unbound fractions of RPG in plasma $\left(f_{u P}\right)$ and liver microsomes $\left(f_{u M I C}\right)$ in the absence or presence of QCT, and the blood-to-plasma concentration ratios $\left(\mathrm{R}_{\mathrm{B}}\right)$ of $\mathrm{RPG}$ in rat and human whole blood in the absence or presence of QCT. The rectangular bars and their error bars represent the means and standard deviations, respectively $(n=5)$.

\subsection{Hepatic Microsomal Metabolism of RPG}

The concentration dependence of RPG metabolism in the RLM and HLM was also investigated. As shown in Figure 3, saturable and concentration-dependent metabolic profiles were observed and well-described via Michaelis-Menten kinetics in both RLM and HLM, assuming the presence of one saturable component $\left(r^{2}=0.982-0.996\right)$. The $\mathrm{V}_{\max }$, $\mathrm{K}_{\mathrm{m}}$, and $C \mathrm{~L}_{\mathrm{int}}$ of RPG in the RLM were estimated to be $1990-4560 \mathrm{pmol} / \mathrm{min} / \mathrm{mg}$ protein, 16.0-92.2 $\mu \mathrm{M}$, and $49.5-124 \mu \mathrm{L} / \mathrm{min} / \mathrm{mg}$ protein, respectively. The $\mathrm{V}_{\max }, \mathrm{K}_{\mathrm{m}}$, and $\mathrm{CL}_{\text {int }}$ of RPG in the HLM were estimated to be $2380-3240 \mathrm{pmol} / \mathrm{min} / \mathrm{mg}$ protein, $27.0-69.4 \mu \mathrm{M}$, and $46.6-89.2 \mu \mathrm{L} / \mathrm{min} / \mathrm{mg}$ protein, respectively. There were no significant differences in the metabolic parameters of RPG between RLM and HLM ( $p=0.656$ for $\mathrm{V}_{\max }, 0.972$ for $\mathrm{K}_{\mathrm{m}}$, and 0.394 for $\left.\mathrm{CL}_{\text {int }}\right)$, indicating negligible species differences.

\subsection{Effects of QCT on the Hepatic Microsomal Metabolism of RPG}

The inhibitory effects of QCT at various concentrations up to $200 \mu \mathrm{M}$ on the metabolism of QCT in RLM and HLM were assessed by constructing dose-response curves (Figure 4). They were readily described using the sigmoidal logistic equation (Equation (3); $r^{2}=0.990-0.999$ ). The mean (range) of the $\mathrm{IC}_{50}$ of QCT on the microsomal metabolism of RPG was estimated to be 16.7 (13.0-18.6) $\mu \mathrm{M}$ in RLM and 3.03 (1.53-5.44) $\mu \mathrm{M}$ in HLM (Table 1). The IC ${ }_{50}$ values were significantly lower in the HLM than in the RLM ( $\left.p=0.000133\right)$. The inhibition mechanism of QCT on RPG metabolism was assessed through the construction of Dixon plots. In both RLM (Figure 5A) and HLM (Figure 5B), the plot lines intersected at a point near the $x$-axis in the upper-left quadrant of the plot, indicating mixed inhibition [38]. The $\mathrm{K}_{\mathrm{i}}$ of QCT on the microsomal metabolism of RPG was estimated by fitting the data to the mixed inhibition model equation (Equation (4)), as listed in Table 1. 


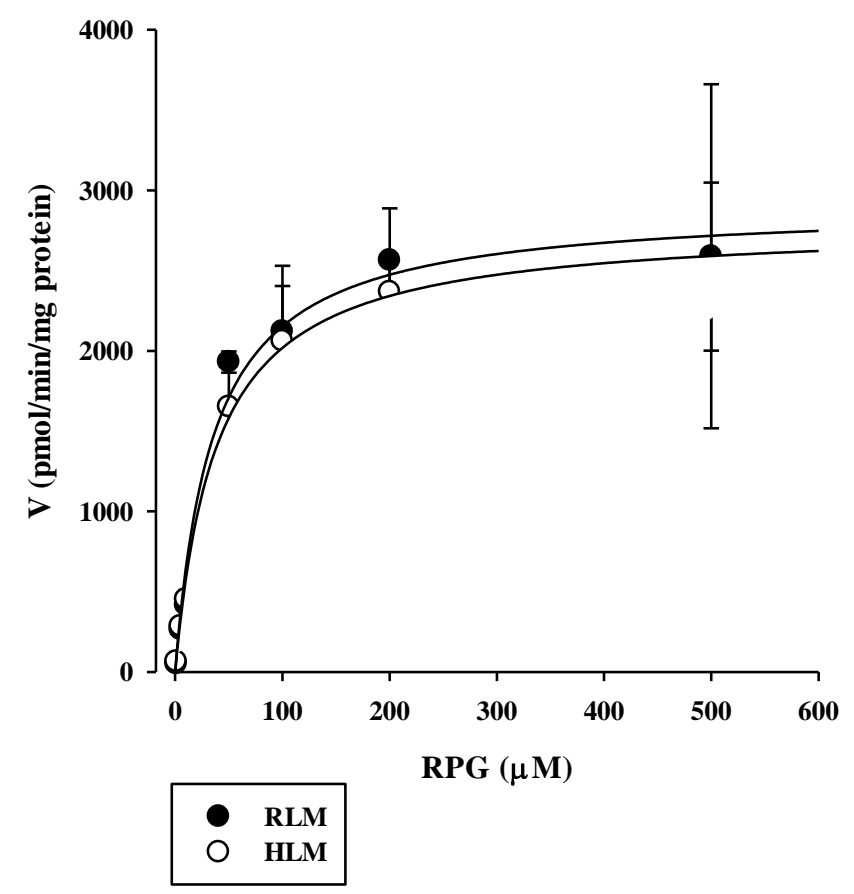

Figure 3. Concentration dependence of the disappearance of RPG in RLM and HLM. The closed circles and their error bars represent the means and standard deviations, respectively $(n=4)$. The solid lines represent the fitted nonlinear regression curves.

\subsection{In Vivo Intravenous and Oral Pharmacokinetic Studies in Rats}

The plasma concentration versus time profiles of intravenous RPG with or without the concurrent administration of intravenous QCT in rats are shown in Figure 6, and the relevant pharmacokinetic parameters are listed in Table 2. The AUC and $t_{1 / 2}$ of RPG were significantly higher by $83.4 \%(p<0.0001)$ and $40.8 \%(p=0.0022)$, respectively, whereas its CL was significantly lower by $44.9 \%(p<0.0001)$ in rats with concurrent administration of QCT than in control rats. There were no significant differences in the $V_{\text {ss }}$ of RPG between the two groups $(p=0.061)$. The plasma concentration versus time profiles of oral RPG with or without the concurrent administration of oral QCT in rats are shown in Figure 7, and the relevant pharmacokinetic parameters are listed in Table 3. The AUC and $C_{\max }$ of RPG were significantly higher by $87.6 \%$ and $84.2 \%$, respectively, in rats that received a concurrent administration of QCT than in control rats ( $p=0.000263$ and 0.00479 , respectively).

Table 1. Enzyme kinetic parameters for the metabolism of RPG and its inhibition by QCT in RLM and HLM.

\begin{tabular}{ccc}
\hline Parameter & RLM & HLM \\
\hline & Metabolism of RPG & $2850 \pm 417$ \\
$\mathrm{~V}_{\max }(\mathrm{pmol} / \mathrm{min} / \mathrm{mg}$ protein $)$ & $3070 \pm 960$ & $42.8 \pm 16.7$ \\
$\mathrm{~K}_{\mathrm{m}}(\mu \mathrm{M})$ & $43.3 \pm 29.7$ & $71.8 \pm 17.7$ \\
$\mathrm{CL}_{\text {int }}(\mu \mathrm{L} / \mathrm{min} / \mathrm{mg}$ protein $)$ & $85.5 \pm 29.2$ & $3.03 \pm 1.84 *$ \\
& Inhibition of RPG metabolism by QCT & 24.2 \\
$\mathrm{IC}_{50}(\mu \mathrm{M})$ & $16.7 \pm 2.6$ & 14.4 \\
$\mathrm{~K}_{\mathrm{i}}(\mu \mathrm{M})$ & 72.0 & Mixed \\
$\alpha$ & 2.88 & Mixed \\
Type & $*$ Siged & \\
\hline
\end{tabular}

* Significantly different from the 'RLM' group $(p<0.05)$. 


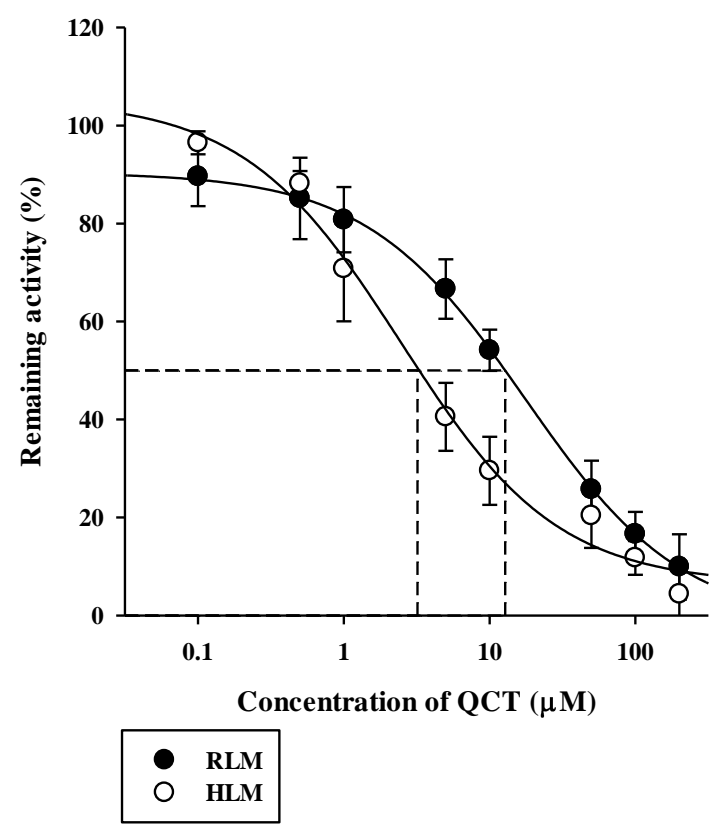

Figure 4. Dose versus response curves for the inhibitory effect of QCT on the disappearance of RPG of $3 \mu \mathrm{M}$ (well below its $K_{m}$ of $43 \mu \mathrm{M}$ ) in RLM and HLM. The closed circles and their error bars represent the means and standard deviations, respectively $(n=4)$. The solid lines represent the fitted nonlinear regression curves.

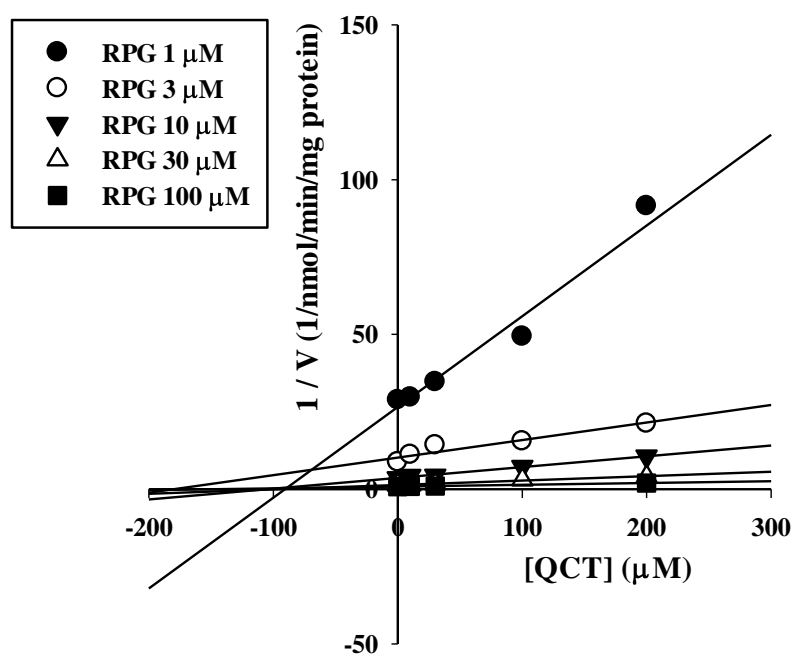

(A)

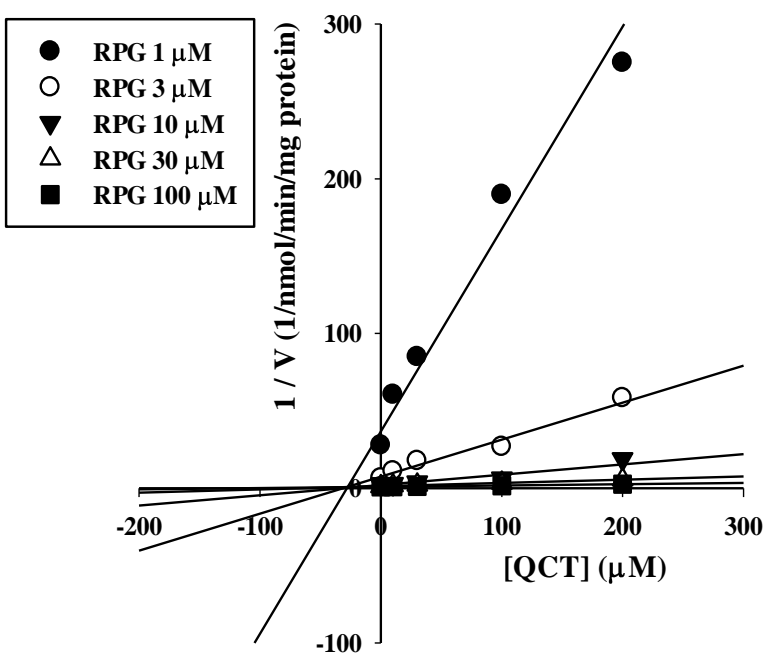

(B)

Figure 5. Dixon plots for the inhibitory effects of QCT on the metabolism of RPG in RLM (A) and HLM (B).

Table 2. Pharmacokinetic parameters of RPG following its intravenous administration at $0.4 \mathrm{mg} / \mathrm{kg}$ without or with simultaneous intravenous administration of QCT at $25 \mathrm{mg} / \mathrm{kg}$ in rats $(n=7)$.

\begin{tabular}{ccc}
\hline Parameter & RPG alone & RPG with QCT \\
\hline $\mathrm{AUC}(\mu \mathrm{g} \cdot \mathrm{min} / \mathrm{mL})$ & $50.7 \pm 3.0$ & $92.9 \pm 11.8^{*}$ \\
$\mathrm{t}_{1 / 2}(\mathrm{~min})$ & $40.8 \pm 4.2$ & $57.4 \pm 10.6^{*}$ \\
$\mathrm{CL}(\mathrm{mL} / \mathrm{min} / \mathrm{kg})$ & $7.92 \pm 0.47$ & $4.36 \pm 0.54^{*}$ \\
$\mathrm{Ae}_{\mathrm{U}}(\%$ of dose$)$ & $1.60 \pm 0.77$ & $1.32 \pm 0.88$ \\
$\mathrm{Ae}_{\mathrm{GI}}(\%$ of dose $)$ & $\mathrm{ND}$ & $\mathrm{ND}$ \\
$\mathrm{V}_{\mathrm{ss}}(\mathrm{mL} / \mathrm{kg})$ & $293 \pm 18$ & $269 \pm 25$ \\
\hline
\end{tabular}

* Significantly different from the control (RPG alone) group $(p<0.05)$. 


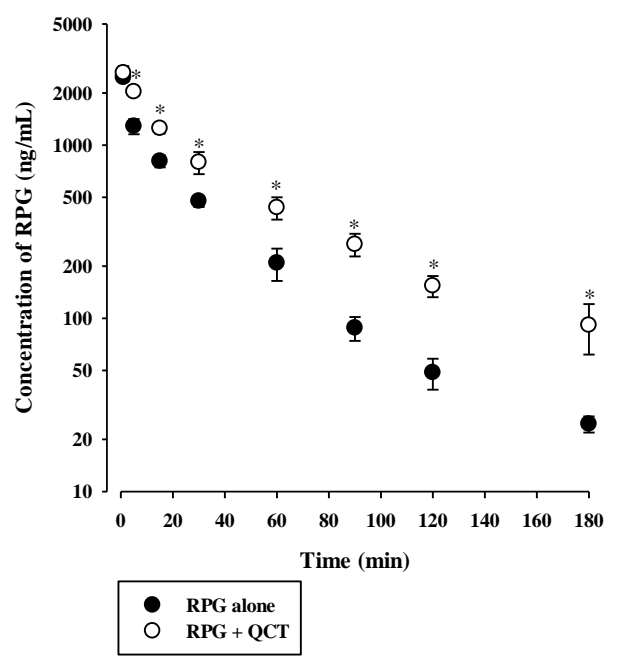

Figure 6. Plasma concentration versus time profiles of RPG following its intravenous administration at $0.4 \mathrm{mg} / \mathrm{kg}$ without or with intravenous QCT at $25 \mathrm{mg} / \mathrm{kg}$ in rats. The circles and their error bars represent the means and standard deviations, respectively $(n=7)$. The asterisks indicate statistical significance when compared to the control (RPG alone) group $(p<0.05)$.

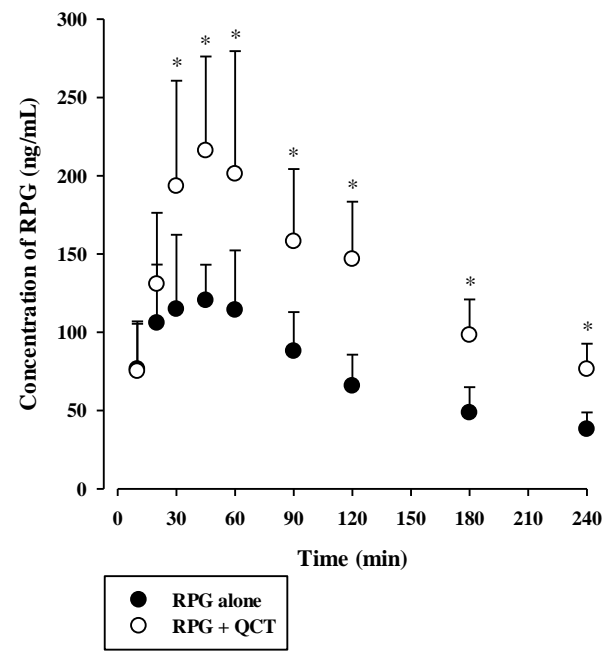

Figure 7. Plasma concentration versus time profiles of RPG following its oral administration at $0.4 \mathrm{mg} / \mathrm{kg}$ without or with oral QCT at $100 \mathrm{mg} / \mathrm{kg}$ in rats. The circles and their error bars represent the means and standard deviations, respectively $(n=7)$. The asterisks indicate statistical significance when compared to the control (RPG alone) group $(p<0.05)$.

Table 3. Pharmacokinetic parameters of RPG following its oral administration at $0.4 \mathrm{mg} / \mathrm{kg}$ without or with simultaneous oral administration of QCT at $100 \mathrm{mg} / \mathrm{kg}$ in rats $(n=7)$.

\begin{tabular}{ccc}
\hline Parameter & RPG Alone & RPG with QCT \\
\hline $\mathrm{AUC}(\mu \mathrm{g} \cdot \mathrm{min} / \mathrm{mL})$ & $25.7 \pm 6.6$ & $48.2 \pm 9.6^{*}$ \\
$\mathrm{t}_{1 / 2}(\mathrm{~min})$ & $139 \pm 66$ & $148 \pm 49$ \\
$\mathrm{C}_{\max }(\mathrm{ng} / \mathrm{mL})$ & $129 \pm 33$ & $238 \pm 76^{*}$ \\
$\mathrm{~T}_{\max }(\mathrm{min})$ & $45(30-45)$ & $45(30-60)$ \\
$\mathrm{Ae}_{\mathrm{U}}(\%$ of dose $)$ & $0.458 \pm 0.441$ & $0.371 \pm 0.336$ \\
$\mathrm{Ae}_{\mathrm{GI}}(\%$ of dose $)$ & $3.41 \pm 1.65$ & $2.90 \pm 2.50$ \\
$\mathrm{~F}(\%)$ & 50.7 & 95.1 \\
\hline
\end{tabular}

* Significantly different from the control (RPG alone) group $(p<0.05)$. 


\section{Discussion}

This study aimed to systematically investigate the potential metabolic drug-phytochemical interactions between RPG and QCT. A previous study reported that the metabolism of RPG (at 0.2 and $2 \mu \mathrm{M}$ ) in HLM was significantly inhibited by the presence of $25 \mu \mathrm{M}$ QCT [8]. To our knowledge, however, the present study is the first systematic investigation of the kinetic mechanisms of the inhibitory actions of QCT on the metabolism of RPG and their possible species differences. Since CYP2C8- and CYP3A4-mediated metabolism are principally responsible for the elimination of RPG in humans [7,8], the results of the present in vitro microsomal metabolic interaction studies can be interpreted and discussed based on the principles and guidelines of CYP-mediated drug-drug interactions. The apparent $K_{i}$ values represent the dissociation constant for the interaction between the inhibitor and the enzyme [39]. As the concentration of the inhibitor (QCT) increased from $0 \mu \mathrm{M}$ to $200 \mu \mathrm{M}$ in the present $\mathrm{K}_{\mathrm{i}}$ estimation study, the $\mathrm{V}_{\max }$ of RPG metabolism tended to decrease (RLM: 2016 to $928 \mathrm{pmol} / \mathrm{min} / \mathrm{mg}$ protein; HLM: 1507 to $818 \mathrm{pmol} / \mathrm{min} / \mathrm{mg}$ protein) and the $\mathrm{K}_{\mathrm{m}}$ of RPG metabolism tended to increase (RLM: 53 to $81 \mu \mathrm{M}$; HLM: 23 to $111 \mu \mathrm{M}$ ). These results are typical diagnostic signatures of mixed inhibition [40], which are consistent with the graphical analysis of the constructed Dixon plots (Figure 5). A mixed inhibitor can bind to the enzyme-substrate complex as well as free enzymes, but it has a higher affinity for one state than the other [41]. In our present results, the $\alpha$ value (representing the extent to which the binding affinity between enzyme and substrate is changed by the inhibitor) was much greater than 1, implying that the inhibitor (QCT) may bind with a higher affinity to the free enzyme (CYP2C8/3A4) than the enzyme-substrate (RPG) complex [42]. Collectively, it is plausible that QCT can inhibit the hepatic metabolism of RPG in vitro via a mixed mechanism and the inhibition potency is weak in rats and moderate in humans.

To investigate the in vivo consequences of the aforementioned in vitro metabolic inhibition data, the pharmacokinetics of RPG with or without concurrent administration of QCT was assessed in rats. The in vivo intravenous and oral doses of RPG and QCT were selected based on previous rat pharmacokinetic studies [43-46]. In our present rat study, the urinary and fecal excretion of RPG administered intravenously was negligible ( $\leq 1.60 \%$ of the dose) [36], suggesting that RPG is primarily eliminated via metabolic routes. Assuming that RPG is metabolized exclusively by the liver, the hepatic clearance $\left(\mathrm{CL}_{\mathrm{H}}\right)$ of RPG becomes equivalent to its blood clearance (calculated as $C L / R_{B}=9.11 \mathrm{~mL} / \mathrm{min} / \mathrm{kg}$ ). Thus, the hepatic extraction ratio $\left(\mathrm{E}_{\mathrm{H}}\right)$ of RPG can be estimated to be $0.114-0.182$, by dividing the $\mathrm{CL}_{\mathrm{H}}$ by the rat hepatic blood flow $\left(\mathrm{Q}_{\mathrm{H}}, 50-80 \mathrm{~mL} / \mathrm{min} / \mathrm{kg}\right)$ [47]. The $\mathrm{CL}_{\mathrm{H}}$ of a drug with a low $\mathrm{E}_{\mathrm{H}}$ primarily depends on its unbound fraction in the blood $\left(\mathrm{f}_{\mathrm{B}}\right)$ and $\mathrm{CL}_{\text {int }}$, based on the well-stirred hepatic clearance model. Because the $f_{B}\left(=f_{P} / R_{B}\right)$ of RPG was not significantly altered by the presence of QCT, the reduced CL of intravenous RPG by the co-administration of QCT (Table 1) could be attributed to a decrease in the $\mathrm{CL}_{\text {int }}$ of RPG, resulting from the observed inhibitory effects of QCT on RPG metabolism.

The F of RPG was known to be approximately $62.5 \%$ in humans [6], which coincides closely with that observed in the present rat study (Table 3). F can be determined by the fraction absorbed $\left(\mathrm{F}_{\mathrm{abs}}\right)$, intestinal availability $\left(\mathrm{F}_{\mathrm{G}}\right)$, and hepatic availability $\left(\mathrm{F}_{\mathrm{H}}\right)$ as follows: $\mathrm{F}=\mathrm{F}_{\mathrm{abs}} \times \mathrm{F}_{\mathrm{G}} \times \mathrm{F}_{\mathrm{H}}=\mathrm{F}_{\text {abs }} \times\left(1-\mathrm{E}_{\mathrm{G}}\right) \times\left(1-\mathrm{E}_{\mathrm{H}}\right)$, where $\mathrm{E}_{\mathrm{G}}$ is the GI extraction ratio. Consistent with intravenous RPG, the fecal excretion of oral RPG was observed to be minimal (2.21-5.78\% of the dose administered). Thus, $\mathrm{F}_{\mathrm{abs}}$ can be assumed to be 1 , and the $\mathrm{F}_{\mathrm{H}}$ of RPG in rats can be estimated to be $0.818-0.886$ from our present rat data. The $\mathrm{F}_{\mathrm{G}}$ of RPG can be calculated to be $0.572-0.620$ in rats using the equation mentioned above, suggesting that considerable gut first-pass effects of RPG may occur, which warrants further investigation. Thus, in our present oral study using a combination of RPG and QCT, it is plausible that the gut and hepatic first-pass and hepatic systemic metabolism of RPG could have been inhibited by QCT, resulting in the increased systemic exposure (AUC and $\mathrm{C}_{\max }$ ) of RPG.

Notably, oral administration of QCT increased the AUC of orally administered RPG by 1.88-fold, indicating that QCT can be classified as an weak inhibitor of in vivo metabolism 
and systemic exposure of RPG in rats [48]. This suggests that a single oral QCT dose of $100 \mathrm{mg} / \mathrm{kg}$ achieved GI and hepatic QCT levels sufficient to significantly inhibit the first-pass and systemic metabolism of RPG in vivo. Previous clinical studies have reported controversial results regarding the pharmacokinetic interactions between QCT and therapeutic drugs. In healthy subjects, oral treatment with QCT at $500 \mathrm{mg} /$ day for 21 days did not significantly change the pharmacokinetics of rosiglitazone [49], whereas the systemic exposure ( $\mathrm{AUC}$ and/or $\mathrm{C}_{\max }$ ) of chlorzoxazone and caffeine were significantly increased by oral treatment with QCT at $1000 \mathrm{mg} /$ day for 10 days and $500 \mathrm{mg} /$ day for 14 days, respectively [14,50]. Based on the FDA guidelines [51], the magnitude of in vivo clinical herb-drug interactions between RPG and QCT was predicted from the in vitro protein binding and metabolism data. The ratio of the AUC of RPG in the presence and absence of QCT was predicted to be 1.03-1.54 by the basic (simple static) model (for a detailed calculation process, see Table S3 in the Supplementary Information). This suggests that QCT could act as a significant inhibitor for RPG metabolism in clinical settings, and there is a possibility that clinically significant pharmacokinetic interactions between QCT and RPG could occur, depending on the extent and duration of QCT intake from food products and dietary supplements.

\section{Conclusions}

This study clearly indicates that QCT can inhibit the hepatic metabolism of RPG in vitro via a mixed mechanism. Furthermore, the in vivo systemic exposure of RPG following intravenous and oral administration in rats was significantly increased by the concurrent administration of QCT. Based on the FDA guidelines, the magnitude of in vivo clinical herb-drug interactions between RPG and QCT was predicted to be a 1.03-1.54-fold increase in the AUC of RPG. These results suggest that clinically significant pharmacokinetic interactions between QCT and RPG could occur, which warrant further systematic clinical investigation.

Supplementary Materials: The following are available online at https:/ /www.mdpi.com/article/ 10.3390/pharmaceutics13060782/s1, Figure S1: Cornish-Bowden plots for the inhibitory effects of QCT on the metabolism of RPG in RLM and HLM, Table S1: Within-run and between-run precision and accuracy of the present bioanalytical method for the quantification of RPG in biological matrices, Table S2: Within-run and between-run precision and accuracy of the present bioanalytical method for the quantification of QCT in biological matrices, Table S3: Parameters related to the estimation of $R$ value. References $[51,52]$ are cited in the supplementary materials.

Author Contributions: Conceptualization, J.-M.K., S.-W.S., H.Y. and I.-S.Y.; Data curation, J.-M.K. and S.-W.S.; Formal analysis, J.-M.K., S.-W.S. and D.-G.H.; Funding acquisition, H.Y. and I.-S.Y.; Investigation, J.-M.K., S.-W.S. and D.-G.H.; Methodology, J.-M.K. and S.-W.S.; Project administration, I.-S.Y.; Software, J.-M.K., S.-W.S. and H.Y.; Supervision, H.Y. and I.-S.Y.; Validation, J.-M.K. and S.-W.S.; Writing —original draft, J.-M.K.; Writing—review and editing, H.Y. and I.-S.Y. All authors have read and agreed to the published version of the manuscript.

Funding: This work was supported by the National Research Foundation of Korea (NRF) grants funded by the Ministry of Science and ICT (NRF-2020R1C1C1011061) and the Bio \& Medical Technology Development Program of the National Research Foundation (NRF) funded by the Korea government (MSIT) (NRF-2017M3A9G7072568).

Institutional Review Board Statement: The study was approved by the Institutional Animal Care and Use Committee at Pusan National University (approval number: PNU-2019-2217, date of approval: 17 April 2019).

Informed Consent Statement: Not applicable.

Data Availability Statement: The data presented in this study are available in the paper.

Conflicts of Interest: The authors declare no conflict of interest. 


\section{References}

1. Marbury, T.C.; Ruckle, J.L.; Hatorp, V.; Andersen, M.P.; Nielsen, K.K.; Huang, W.C.; Strange, P. Pharmacokinetics of repaglinide in subjects with renal impairment. Clin. Pharmacol. Ther. 2000, 67,7-15. [CrossRef]

2. Sekhar, M.C.; Reddy, P.J. Influence of atorvastatin on the pharmacodynamic and pharmacokinetic activity of repaglinide in rats and rabbits. Mol. Cell Biochem. 2012, 364, 159-164. [CrossRef]

3. Riefflin, A.; Ayyagari, U.; Manley, S.E.; Holman, R.R.; Levy, J.C. The effect of glibenclamide on insulin secretion at normal glucose concentrations. Diabetologia 2015, 58, 43-49. [CrossRef]

4. Campbell, I.W. Nateglinide-current and future role in the treatment of patients with type 2 diabetes mellitus. Int. J. Clin. Pract. 2005, 59, 1218-1228. [CrossRef]

5. Tankova, T.; Koev, D.; Dakovska, L.; Kirilov, G. The effect of repaglinide on insulin secretion and oxidative stress in type 2 diabetic patients. Diabetes Res. Clin. Pract. 2003, 59, 43-49. [CrossRef]

6. Hatorp, V.; Oliver, S.; Su, C.A. Bioavailability of repaglinide, a novel antidiabetic agent, administered orally in tablet or solution form or intravenously in healthy male volunteers. Int. J. Clin. Pharmacol. Ther. 1998, 36, 636-641.

7. Bidstrup, T.B.; Bjornsdottir, I.; Sidelmann, U.G.; Thomsen, M.S.; Hansen, K.T. CYP2C8 and CYP3A4 are the principal enzymes involved in the human in vitro biotransformation of the insulin secretagogue repaglinide. Br. J. Clin. Pharmacol. 2003, 56, 305-314. [CrossRef]

8. Kajosaari, L.I.; Laitila, J.; Neuvonen, P.J.; Backman, J.T. Metabolism of repaglinide by CYP2C8 and CYP3A4 in vitro: Effect of fibrates and rifampicin. Basic Clin. Pharmacol. Toxicol. 2005, 97, 249-256. [CrossRef] [PubMed]

9. Egert, S.; Rimbach, G. Which sources of flavonoids: Complex diets or dietary supplements? Adv. Nutr. 2011, 2, 8-14. [CrossRef] [PubMed]

10. Han, D.-G.; Cho, S.-S.; Kwak, J.-H.; Yoon, I.-S. Medicinal plants and phytochemicals for diabetes mellitus: Pharmacokinetic characteristics and herb-drug interactions. J. Pharm. Investig. 2019, 49, 603-612. [CrossRef]

11. Chang, H.Y.; Wallis, M.; Tiralongo, E. Use of complementary and alternative medicine among people living with diabetes: Literature review. J. Adv. Nurs. 2007, 58, 307-319. [CrossRef]

12. Gruse, J.; Gors, S.; Tuchscherer, A.; Otten, W.; Weitzel, J.M.; Metges, C.C.; Wolffram, S.; Hammon, H.M. The effects of oral quercetin supplementation on splanchnic glucose metabolism in 1-week-old calves depend on diet after birth. J. Nutr. 2015, 145, 2486-2495. [CrossRef]

13. Hatahet, T.; Morille, M.; Hommoss, A.; Dorandeu, C.; Muller, R.H.; Begu, S. Dermal quercetin smartCrystals(R): Formulation development, antioxidant activity and cellular safety. Eur. J. Pharm. Biopharm. 2016, 102, 51-63. [CrossRef]

14. Bedada, S.K.; Neerati, P. The effect of quercetin on the pharmacokinetics of chlorzoxazone, a CYP2E1 substrate, in healthy subjects. Eur. J. Clin. Pharmacol. 2018, 74, 91-97. [CrossRef] [PubMed]

15. D'Andrea, G. Quercetin: A flavonol with multifaceted therapeutic applications? Fitoterapia 2015, 106, 256-271. [CrossRef] [PubMed]

16. Eid, H.M.; Haddad, P.S. The antidiabetic potential of quercetin: Underlying mechanisms. Curr. Med. Chem. 2017, 24, 355-364. [PubMed]

17. Almeida, A.F.; Borge, G.I.A.; Piskula, M.; Tudose, A.; Tudoreanu, L.; Valentová, K.; Williamson, G.; Santos, C.N. Bioavailability of quercetin in humans with a focus on interindividual variation. Compr. Rev. Food Sci. Food Saf. 2018, 17, 714-731. [CrossRef]

18. Komatsu, T.; Yamazaki, H.; Shimada, N.; Nakajima, M.; Yokoi, T. Roles of cytochromes P450 1A2, 2A6, and 2C8 in 5-fluorouracil formation from tegafur, an anticancer prodrug, in human liver microsomes. Drug Metab. Dispos. 2000, 28, 1457-1463.

19. Marill, J.; Capron, C.C.; Idres, N.; Chabot, G.G. Human cytochrome P450s involved in the metabolism of 9-cis- and 13-cis-retinoic acids. Biochem. Pharmacol. 2002, 63, 933-943. [CrossRef]

20. Projean, D.; Baune, B.; Farinotti, R.; Flinois, J.P.; Beaune, P.; Taburet, A.M.; Ducharme, J. In vitro metabolism of chloroquine: Identification of CYP2C8, CYP3A4, and CYP2D6 as the main isoforms catalyzing N-desethylchloroquine formation. Drug Metab. Dispos. 2003, 31, 748-754. [CrossRef]

21. Obach, R.S. Inhibition of human cytochrome P450 enzymes by constituents of St. John's Wort, an herbal preparation used in the treatment of depression. J. Pharmacol. Exp. Ther. 2000, 294, 88-95.

22. Zou, L.; Harkey, M.R.; Henderson, G.L. Effects of herbal components on cDNA-expressed cytochrome P450 enzyme catalytic activity. Life Sci. 2002, 71, 1579-1589. [CrossRef]

23. Walsky, R.L.; Obach, R.S.; Gaman, E.A.; Gleeson, J.P.; Proctor, W.R. Selective inhibition of human cytochrome P4502C 8 by montelukast. Drug Metab. Dispos. 2005, 33, 413-418. [CrossRef]

24. Ostlund, J.; Zlabek, V.; Zamaratskaia, G. In vitro inhibition of human CYP2E1 and CYP3A by quercetin and myricetin in hepatic microsomes is not gender dependent. Toxicology 2017, 381, 10-18. [CrossRef]

25. Niemi, M.; Kajosaari, L.I.; Neuvonen, M.; Backman, J.T.; Neuvonen, P.J. The CYP2C8 inhibitor trimethoprim increases the plasma concentrations of repaglinide in healthy subjects. Br. J. Clin. Pharmacol. 2004, 57, 441-447. [CrossRef]

26. Tornio, A.; Filppula, A.M.; Kailari, O.; Neuvonen, M.; Nyronen, T.H.; Tapaninen, T.; Neuvonen, P.J.; Niemi, M.; Backman, J.T. Glucuronidation converts clopidogrel to a strong time-dependent inhibitor of CYP2C8: A phase II metabolite as a perpetrator of drug-drug interactions. Clin. Pharmacol. Ther. 2014, 96, 498-507. [CrossRef]

27. Niemi, M.; Backman, J.T.; Neuvonen, M.; Neuvonen, P.J. Effects of gemfibrozil, itraconazole, and their combination on the pharmacokinetics and pharmacodynamics of repaglinide: Potentially hazardous interaction between gemfibrozil and repaglinide. Diabetologia 2003, 46, 347-351. [CrossRef] [PubMed] 
28. Kajosaari, L.I.; Niemi, M.; Backman, J.T.; Neuvonen, P.J. Telithromycin, but not montelukast, increases the plasma concentrations and effects of the cytochrome P450 3A4 and 2C8 substrate repaglinide. Clin. Pharmacol. Ther. 2006, 79, 231-242. [CrossRef] [PubMed]

29. VandenBrink, B.M.; Foti, R.S.; Rock, D.A.; Wienkers, L.C.; Wahlstrom, J.L. Evaluation of CYP2C8 inhibition in vitro: Utility of montelukast as a selective CYP2C8 probe substrate. Drug Metab. Dispos. 2011, 39, 1546-1554. [CrossRef] [PubMed]

30. Kim, S.B.; Lee, T.; Lee, H.S.; Song, C.K.; Cho, H.J.; Kim, D.D.; Maeng, H.J.; Yoon, I.S. Development and validation of a highly sensitive LC-MS/MS method for the determination of acacetin in human plasma and its application to a protein binding study. Arch. Pharm. Res. 2016, 39, 213-220. [CrossRef] [PubMed]

31. Isbell, J.; Yuan, D.; Torrao, L.; Gatlik, E.; Hoffmann, L.; Wipfli, P. Plasma Protein Binding of Highly Bound Drugs Determined With Equilibrium Gel Filtration of Nonradiolabeled Compounds and LC-MS/MS Detection. J. Pharm. Sci. 2019, 108, 1053-1060. [CrossRef] [PubMed]

32. Riccardi, K.; Cawley, S.; Yates, P.D.; Chang, C.; Funk, C.; Niosi, M.; Lin, J.; Di, L. Plasma Protein Binding of Challenging Compounds. J. Pharm. Sci. 2015, 104, 2627-2636. [CrossRef] [PubMed]

33. Kalvass, J.C.; Maurer, T.S. Influence of nonspecific brain and plasma binding on CNS exposure: Implications for rational drug discovery. Biopharm. Drug Dispos. 2002, 23, 327-338. [CrossRef]

34. Yoon, I.; Han, S.; Choi, Y.H.; Kang, H.E.; Cho, H.J.; Kim, J.S.; Shim, C.K.; Chung, S.J.; Chong, S.; Kim, D.D. Saturable sinusoidal uptake is rate-determining process in hepatic elimination of docetaxel in rats. Xenobiotica 2012, 42, 1110-1119. [CrossRef]

35. Kim, J.E.; Cho, H.J.; Kim, J.S.; Shim, C.K.; Chung, S.J.; Oak, M.H.; Yoon, I.S.; Kim, D.D. The limited intestinal absorption via paracellular pathway is responsible for the low oral bioavailability of doxorubicin. Xenobiotica 2013, 43, 579-591. [CrossRef] [PubMed]

36. Han, D.G.; Kwak, J.; Seo, S.W.; Kim, J.M.; Yoo, J.W.; Jung, Y.; Lee, Y.H.; Kim, M.S.; Jung, Y.S.; Yun, H.; et al. Pharmacokinetic Evaluation of Metabolic Drug Interactions between Repaglinide and Celecoxib by a Bioanalytical HPLC Method for Their Simultaneous Determination with Fluorescence Detection. Pharmaceutics 2019, 11, 382. [CrossRef]

37. Biasutto, L.; Marotta, E.; Garbisa, S.; Zoratti, M.; Paradisi, C. Determination of quercetin and resveratrol in whole bloodimplications for bioavailability studies. Molecules 2010, 15, 6570-6579. [CrossRef]

38. Zhang, D.; Zhu, M.; Humphreys, W.G. Drug Metabolism in Drug Design and Development: Basic Concepts and Practice; John Wiley \& Sons, Inc.: Hoboken, NJ, USA, 2007.

39. Kim, S.B.; Kim, K.S.; Kim, D.D.; Yoon, I.S. Metabolic interactions of rosmarinic acid with human cytochrome P450 monooxygenases and uridine diphosphate glucuronosyltransferases. Biomed. Pharmacother. 2019, 110, 111-117. [CrossRef] [PubMed]

40. Santos, J.A.; Kondo, M.Y.; Freitas, R.F.; dos Santos, M.H.; Ramalho, T.C.; Assis, D.M.; Juliano, L.; Juliano, M.A.; Puzer, L. The natural flavone fukugetin as a mixed-type inhibitor for human tissue kallikreins. Bioorg. Med. Chem. Lett. 2016, 26, 1485-1489. [CrossRef]

41. Copeland, R.A.; Horiuchi, K.Y. Kinetic effects due to nonspecific substrate-inhibitor interactions in enzymatic reactions. Biochem. Pharmacol. 1998, 55, 1785-1790. [CrossRef]

42. Kim, S.B.; Cho, H.J.; Kim, Y.S.; Kim, D.D.; Yoon, I.S. Modulation of Cytochrome P450 Activity by 18beta-Glycyrrhetic Acid and its Consequence on Buspirone Pharmacokinetics in Rats. Phytother. Res. 2015, 29, 1188-1194. [CrossRef]

43. Xu, Y.; Zhou, D.; Wang, Y.; Li, J.; Wang, M.; Lu, J.; Zhang, H. CYP2C8-mediated interaction between repaglinide and steviol acyl glucuronide: In vitro investigations using rat and human matrices and in vivo pharmacokinetic evaluation in rats Food Chem. Toxicol. 2016, 94, 138-147. [CrossRef] [PubMed]

44. Choi, J.S.; Choi, I.; Choi, D.H. Effects of nifedipine on the pharmacokinetics of repaglinide in rats: Possible role of CYP3A4 and P-glycoprotein inhibition by nifedipine. Pharmacol. Rep. 2013, 65, 1422-1430. [CrossRef]

45. Yang, L.L.; Xiao, N.; Li, X.W.; Fan, Y.; Alolga, R.N.; Sun, X.Y.; Wang, S.L.; Li, P.; Qi, L.W. Pharmacokinetic comparison between quercetin and quercetin 3-O-beta-glucuronide in rats by UHPLC-MS/MS. Sci. Rep. 2016, 6, 35460. [CrossRef]

46. Liu, Y.; Luo, X.; Yang, C.; Yang, T.; Zhou, J.; Shi, S. Impact of quercetininduced changes in drugmetabolizing enzyme and transporter expression on the pharmacokinetics of cyclosporine in rats. Mol. Med. Rep. 2016, 14, 3073-3085. [CrossRef] [PubMed]

47. Seo, S.W.; Park, J.W.; Han, D.G.; Kim, J.M.; Kim, S.; Park, T.; Kang, K.H.; Yang, M.H.; Yoon, I.S. In Vitro and In Vivo Assessment of Metabolic Drug Interaction Potential of Dutasteride with Ketoconazole. Pharmaceutics 2019, 11, 673. [CrossRef] [PubMed]

48. Center for Drug Evaluation and Research. Clinical Interaction Studies: Cytochrome P450 Enzyme- and Transporter-Mediated Drug Interactions. USA Food Drug Adm. Guid. Ind. 2020, 16-21. Available online: https://www.fda.gov/media/134581 / download (accessed on 1 May 2021).

49. Kim, K.A.; Park, P.W.; Kim, H.K.; Ha, J.M.; Park, J.Y. Effect of quercetin on the pharmacokinetics of rosiglitazone, a CYP2C8 substrate, in healthy subjects. J. Clin. Pharmacol. 2005, 45, 941-946. [CrossRef] [PubMed]

50. Xiao, J.; Huang, W.H.; Peng, J.B.; Tan, Z.R.; Ou-Yang, D.S.; Hu, D.L.; Zhang, W.; Chen, Y. Quercetin significantly inhibits the metabolism of caffeine, a substrate of cytochrome P450 1A2 unrelated to CYP1A2*1C (-2964G>A) and *1F (734C>A) gene polymorphisms. Biomed Res. Int. 2014, 2014, 405071. [CrossRef]

51. Center for Drug Evaluation and Research. In Vitro Drug Interaction Studies: Cytochrome P450 Enzyme- and Transporter-Mediated Drug Interactions. USA Food Drug Adm. Guid. Ind. 2020, 2-5. Available online: https://www.fda.gov/media/134582/download (accessed on 1 May 2021).

52. Ganio, M.S.; Armstrong, L.E.; Johnson, E.C.; Klau, J.F.; Ballard, K.D.; Michniak-Kohn, B.; Kaushik, D.; Maresh, C.M. Effect of quercetin supplementation on maximal oxygen uptake in men and women. J. Sports Sci. 2010, 28, 201-208. [CrossRef] [PubMed] 